\title{
Absolute Two-Photon Absorption Spectra and Two-Photon Brightness of Orange and Red Fluorescent Proteins
}

\author{
M. Drobizhev ${ }^{\dagger,}{ }^{*}$, S. Tillo $\ddagger$, N. S. Makarov ${ }^{\dagger}$, T. E. Hughes ${ }^{\ddagger}$, and A. Rebane ${ }^{\dagger, \S}$ \\ $\dagger$ Department of Physics, Montana State University, Bozeman, USA 59717 \\ $\$$ Department of Cell Biology and Neuroscience, Montana State University, Bozeman, USA 59717 \\ $\S N a t i o n a l$ Institute of Chemical Physics and Biophysics, Tallinn, Estonia
}

\begin{abstract}
Fluorescent proteins with long emission wavelengths are particularly attractive for deep tissue twophoton microscopy. Surprisingly little is known about their two-photon absorption (2PA) properties. We present absolute 2PA spectra of a number of orange and red fluorescent proteins, including DsRed2, mRFP, TagRFP, and several mFruit proteins, in a wide range of excitation wavelengths $(640-1400 \mathrm{~nm})$. To evaluate $2 \mathrm{PA}$ cross section $\left(\sigma_{2}\right)$, we use a new method relying only on the optical properties of the intact mature chromophore. In the tuning range of a mode-locked Ti:sapphire laser, $700-1000 \mathrm{~nm}$, TagRFP possesses the highest two-photon cross section, $\sigma_{2}=315 \mathrm{GM}$, and brightness, $\sigma_{2} \varphi=130 \mathrm{GM}$, where $\varphi$ is the fluorescence quantum yield. At longer wavelengths, $1000-1100 \mathrm{~nm}$, tdTomato has the largest values, $\sigma_{2}=216 \mathrm{GM}$ and $\sigma_{2} \varphi=120 \mathrm{GM}$, per protein chain. Compared to the benchmark EGFP, these proteins present 3-4 times improvement in two-photon brightness.
\end{abstract}

Fluorescent proteins (FPs) have revolutionized the way that we image biological systems ${ }^{1}$. Because FPs can be genetically encoded, they can be targeted to specific organelles, cells, and tissues with the precision in ways that dyes cannot, and since they do not damage the cells, they can be imaged repeatedly in living systems. To take full advantage of the opportunities these probes offer, it is often necessary to use two-photon laser scanning microscopy (TPLSM) 2,3 , whose longer wavelengths are better suited for deep imaging. In addition, TPLSM offers less photodamage, less photobleaching, and less autofluorescence background compared to one-photon confocal microscopy. Surprisingly, little is known about which fluorescent proteins are best suited for two-photon induced fluorescence.

Choosing the best FP for TPLSM is a critical issue that requires, among other things, knowledge of the optimum excitation wavelength, $\lambda_{\text {opt }}$, as well as the two-photon brightness, which is defined as the product of the peak two-photon absorption (2PA) cross section $\sigma_{2}$ and the fluorescence quantum yield $\varphi: \sigma_{2}{ }^{\prime}=\sigma_{2} \varphi$. It is important to characterize the 2PA properties of the fluorescent proteins because $\sigma_{2}$ cannot be readily predicted from the one-photon absorption (1PA) strength alone. Furthermore, the peak wavelength of 2PA does not always coincide with twice the wavelength of the 1PA peak. In particular, the short-wavelength shift of 2PA transition maximum with respect to 1PA transition maximum is observed in centrosymmetric and slightly asymmetric molecules with pronounced vibronic structure ${ }^{4}$.

The few available reports on the 2PA properties of FPs $2,3,5-11$ explore a narrow range of excitation wavelengths with often inconsistent results $6,10,11$. Because the orange and red fluorescent proteins are particularly useful for imaging in thick tissues, we decided to

*Corresponding author email: drobizhev@ physics.montana.edu. 
quantitatively study the two-photon excitation properties of a number of orange and red fluorescent proteins, including DsRed2, mRFP ${ }^{12}, \operatorname{TagRFP}^{13}$, and several mFruit proteins ${ }^{14}$, over a wide range of excitation wavelengths and in the same experimental conditions. Here we describe the results which should guide biologists interested in optimizing their TPLSM with fluorescent proteins.

Figure 1 shows the 2PA spectra (symbols) of a series of orange and red FPs together with their corresponding fluorescence emission (blue solid line) and fluorescence excitation (black solid line) spectra. The excitation spectra serve as an effective representation of one-photon absorption, with the advantage that they exclude spurious background due to scattering and absorption by impurities (e.g. immature protein). Note that the top $x$-axis represents the transition wavelength, which is the same for 1PA and 2PA, and that the bottom $x$-axis corresponds to the laser wavelength used for two-photon excitation. The left ordinate axis shows the 2PA cross section and the right ordinate axis - the two-photon brightness, $\sigma_{2} \varphi$.

The 2PA spectra of the FPs studied are generally similar in shape: they consist of two electronic transitions, separated by a distinct minimum near $\lambda_{2 \mathrm{PA}}=780-840 \mathrm{~nm}$. The long wavelength 2PA maxima occurring in the region $1000-1100 \mathrm{~nm}$ are attributed to transition to the lowest energy singlet state, $S_{0} \rightarrow S_{1}$; the short wavelength feature is due to transition to a higher-energy singlet state, $\mathrm{S}_{0} \rightarrow \mathrm{S}_{\mathrm{n}}$.

The structure observed in the $\mathrm{S}_{0} \rightarrow \mathrm{S}_{1} 2 \mathrm{PA}$ band is due to partially resolved vibronic transitions ${ }^{6}$, with effective frequencies $700-1450 \mathrm{~cm}^{-1}$ (obtained as a shift between the most prominent $2 \mathrm{PA}$ peak and the strongest 1PA peak, assigned to $0-0$ transition ${ }^{15}$ ). Note, that the 2PA spectrum also contains the 0-0 transition (observed as a weak shoulder at twice the 1PA peak wavelength), but, compared to 1PA, the intensity is redistributed in favor of blue-shifted vibronic peak, see Fig. 1. An alternative explanation for the blue shift of 2PA peak in EGFP has also been recently presented ${ }^{10}$ and suggests that it is due to another, stronger, electronic transition $\left(\mathrm{S}_{0} \rightarrow \mathrm{S}_{2}\right)$ slightly higher in energy than $\mathrm{S}_{0} \rightarrow \mathrm{S}_{1}$. This assignment seems less probable, because quantum mechanical calculations ${ }^{16}$ show no electronic transitions in such close proximity to $\mathrm{S}_{0} \rightarrow \mathrm{S}_{1}$ transition neither in 1PA nor in 2PA spectra for none of the known FP chromophores (including EGFP). Also, it would be very improbable for several chromophores with different chemical structures that the second electronic transition would always occur this close to the first one and always shifted to the blue by $700-1500 \mathrm{~cm}^{-1}$, (see Fig. 1 and Refs. $3,6,7,9,17$ ). On the other hand, the latter frequency range corresponds to typical intramolecular vibrations, supporting the vibronic nature of 2PA peak.

The peak 2PA cross section in the $\mathrm{S}_{0} \rightarrow \mathrm{S}_{1}$ region varies strongly between the proteins studied here. Intriguingly, even in proteins with the same chromophore structure, such as DsRed, mStrawberry, and mCherry (see crystallography data ${ }^{18,19}$ ), there is a large difference in $2 \mathrm{PA}$ strength. For example, the cross section increases 5 times when going from mStrawberry to DsRed2. We can argue that the local chromophore environment, constituting a delicate hydrogen bonding network, a number of salt bridges, and few charged amino acid residues, which can vary from one mutant to another, see Fig. 2, matters for both one- and two-photon absorption properties. In particular, one-photon absorption spectral changes in the series DsRed - mCherry - mStrawberry, were previously tentatively explained by few structural effects, involving substitution of Lys 83 and Lys 163 with bulky nonpolar groups and changing the protonation state of Glu $215^{19}$. Strong variation of the peak 2PA cross section in a series of FPs with the red chromophore can also be explained by these structural changes in the surrounding. In mOrange protein, the conjugation pattern of the chromophore itself was found to differ from that of DsRed ${ }^{19}$, resulting in a large blue shift of absorption/fluorescence peak. The detailed theoretical description of these effects on 2PA properties will be presented in a forthcoming publication. 
On the short wavelength side, the 2PA spectrum is due to the higher-energy $\mathrm{S}_{0} \rightarrow \mathrm{S}_{\mathrm{n}}$ transition (s). In TagRFP there is a distinct 2PA peak at $\sim 760 \mathrm{~nm}$, which corresponds to a weak peak observed in 1PA spectrum at around $380 \mathrm{~nm}$. Analogous, but less resolved 2PA transitions (revealed as a shoulder) are also observed in other orange and red FPs. Similar shortwavelength features have recently been demonstrated experimentally 17 in GFP, CFP and mRFP, and were also predicted theoretically for a number of FPs with different types of chromophores ${ }^{16}$. The $\mathrm{S}_{0} \rightarrow \mathrm{S}_{\mathrm{n}} 2 \mathrm{PA}$ transition gains in intensity (compared to $\mathrm{S}_{0} \rightarrow \mathrm{S}_{1}$ transition) partially because of (pre-) resonance enhancement ${ }^{16,17}$. This quantum-mechanical effect becomes particularly pronounced when the laser frequency approaches from below the lowestenergy one-photon allowed transition, and the energy of two photons matches the energy of the final state (see Ref. 21 for previous experimental demonstration on other organic molecules). Note that the data shown here were only collected at the wavelengths where the fluorescence signal showed a quadratic dependence on laser power, indicating that hot-band one-photon absorption did not contribute to the 2PA spectrum.

Quantitative evaluation of the 2PA cross section and two-photon brightness is not trivial because one needs, first of all, reliable data on the mature protein concentration, which is difficult to obtain for some FPs by standard methods ${ }^{22}$. For example, BCA or nano-Orange techniques provide only information on the total amount of protein, including immature or/and misfolded species. Since the total molar concentration of protein is always equal or greater than the molar concentration of mature chromophore, the extinction coefficient measured by these methods, while subsequently applying Beer's law, will most probably be underestimated.

Currently, the most reliable method of evaluating FP concentration consists of measuring optical density of a protein at $447 \mathrm{~nm}$ in strongly alkaline conditions and using the extinction coefficient of denatured GFP at $\mathrm{pH} 13$ as a standard ${ }^{18,23}$. However, this method cannot distinguish between green and red chromophores, and can also result in rapid degradation of chromophore on a time scale of minutes, which may again lead to erroneous concentration values $^{22}$.

We reasoned that the most direct measurement of mature chromophore concentration would involve an all-optical approach. Our method is based on the Strickler-Berg (S-B) equation relating molecular extinction coefficient to the fluorescence radiative lifetime, $\tau_{R}$, where the last can be measured by standard time-resolved and steady-state fluorescence techniques. Note that neither the fluorescence lifetime nor the fluorescence quantum efficiency, used for calculation of $\tau_{R}$, depend on concentration of the chromophore. This fact makes it possible to find the extinction coefficient independent of total concentration of protein.

Table 1 summarizes the fluorescence and absorption data relevant to evaluation of the extinction coefficient $\varepsilon_{\max }$ (S-B) using the Strickler-Berg equation. The last column of Table 1 shows, for comparison, the extinction coefficients that we obtained with the standard BCA procedure and alkaline denaturation measurements reported by others. For some proteins the all-optical data (column 7) correlates well with the BCA and alkaline denaturation assays (column 8). For others, e.g. mBanana, the deviations are quite appreciable.

Molar chromophore concentrations were obtained from Beer's law, using $\varepsilon_{\max }(\mathrm{S}-\mathrm{B})$ value, and then 2PA cross sections per chromophore $\sigma_{2}$ were evaluated (SI). These values are used for scaling of spectra in Fig. 1. Table 2 presents the optimum excitation wavelength, corresponding absolute 2PA cross section, and absolute two-photon brightness in two wavelength regions: $640-1000-\mathrm{nm}$ and $1000-1100 \mathrm{~nm}$. Fluorescence maximum wavelength and quantum efficiency are also included.

The results presented here provide a more comprehensive, quantitative view of the two-photon properties of commonly used orange and red fluorescent proteins. The majority of previous 
work $2,3,5-7,10,11$ characterized the two-photon excitation properties of the FPs within the limited tuning range of a Ti:Saphire laser. Our measurements extend over a larger range, and reveal favorable opportunities for the use of other laser systems and excitation wavelengths.

In addition, previous works have produced largely varying results. For example, for the peak 2PA brightness of EGFP at neutral pH, Blab et al. ${ }^{6}$ report $\sigma_{2} \varphi=41 \mathrm{GM}$ (near $920 \mathrm{~nm}$ ), Hosoi et al. ${ }^{10}$ provide $\sigma_{2} \varphi<2 \mathrm{GM}\left(\sigma_{2} \sim 2 \mathrm{GM}\right.$ near $\left.930 \mathrm{~nm}\right)$, and Kawano et al. ${ }^{11}, \sigma_{2} \varphi=175 \mathrm{GM}$ (near $930 \mathrm{~nm}$ ). One possible reason for previous inconsistencies is the difficulty in measuring the concentration of mature chromophore. The all-optical approach introduced here helps avoiding potential artifacts related to incomplete maturation, the presence of unfolded protein, and scattering inherent in working with FPs. While these data are useful in choosing an optimal fluorescent protein for two-photon microscopy, the utility of any one of these reporters may vary depending on the expression system used due to differences in a variety of factors including folding, codon usage, and maturation rate.

Previous descriptions $2,3,5-9,11$ of the two-photon properties of the FPs have presented action excitation cross sections (termed two-photon brightness here), which is the product of $\sigma_{2}$ and $\varphi$. Here we measured $\sigma_{2}$ independent of $\varphi$. Knowing $\sigma_{2}$ is important for two-photon applications of FPs other than microscopy 27,28 .

Inspection of Fig. 1 and Table 2 shows that in the shorter wavelength range TagRFP appears to be the protein of choice for TPLSM. In the Ti:sapphire range of wavelengths, $700-1000$ $\mathrm{nm}$, it shows the 2PA maximum (near $\lambda_{2 \mathrm{PA}}=760 \mathrm{~nm}$ ), with the brightness $\sigma_{2}{ }^{\prime}=130 \mathrm{GM}$, which is almost 4 times as high as that of benchmark EGFP in its spectral maximum $\left(\sigma_{2}{ }^{\prime}=35\right.$ GM at $900 \mathrm{~nm}$, our data (SI) and Ref. 6). TagRFP matures quickly, can be expressed in many different types of organisms, and works well as a fusion partner ${ }^{13}$. Other FP mutants, advantageous for Ti:sapphire range of wavelengths, include, in the order of decreasing brightness per chromophore, DsRed $2>$ tdTomato $>$ mOrange $>$ mBanana.

In the longer wavelength region, $1000-1100 \mathrm{~nm}$, tdTomato is the brightest $\mathrm{FP}, 2 \sigma_{2}{ }^{\prime}=120$ $\mathrm{GM}$ at $1050 \mathrm{~nm}$. DsRed2 shows the largest $\sigma 2$ ' per chromophore (63 GM), although its obligate tetrameric structure can be a drawback when it is used as a fusion partner. The true monomers, TagRFP, mBanana, and mOrange, follow and are all similar in 2PA brightness. The range from 1000 to $1100 \mathrm{~nm}$ is particularly attractive because of decreased absorption in the tissue and less two-photon excited background ${ }^{29}$, but it is inaccessible to Ti:Saphire laser excitation and will require alternative sources, such as Nd- or Yb-doped solid-state lasers.

To date, many mutagenesis efforts have focused on improving the one-photon properties of fluorescent proteins $1,12-14,22,25$. The data collected here reveal that the single-photon properties of the FPs are poor predictors of which fluorescent proteins will be optimal in twophoton applications. It follows that additional mutagenesis efforts to improve two-photon cross section will benefit the field.

\section{Supplementary Material}

Refer to Web version on PubMed Central for supplementary material.

\section{Acknowledgements}

This work was supported by Montana Board Research Commercialization MBRCT grant \# W1726, and NIH/NINDS grant R21NS054270. We thank I. Kochetkova for technical help and P. R. Callis for discussion. 


\section{References}

1. Tsien RY. Annu. Rev. Biochem 1998;67:509. [PubMed: 9759496]

2. Xu C, Zipfel W, Shear JB, Williams RM, Webb WW. Proc. Natl. Acad. Sci. U.S.A 1996;93:10763. [PubMed: 8855254]

3. Zipfel WR, Williams RM, Webb WW. Nat. Biotechnol 2003;21:1369. [PubMed: 14595365]

4. Callis PR. Annu. Rev. Phys. Chem 1997;48:271. [PubMed: 15012446] and references therein

5. Heikal AA, Hess ST, Webb WW. Chem. Phys 2001;274:37.

6. Blab GA, Lommerse PHM, Cognet L, Harms GS, Schmidt T. Chem. Phys. Lett 2001;350:71.

7. Tsai PS, et al. Neuron 2003;39:27. [PubMed: 12848930]

8. Tsai T-H, et al. Opt. Lett 2006;31:930. [PubMed: 16599215]

9. Ivanchenko S, et al. Biophys. J 2007;92:4451. [PubMed: 17384061]

10. Hosoi H, Yamaguchi S, Mizuno H, Miyawaki A, Tahara T. J. Phys. Chem. B 2008;112:2761. [PubMed: 18275187]

11. Kawano H, Kogure T, Abe Y, Mizuno H, Miyawaki A. Nat. Methods 2008;5:373. [PubMed: 18446153]

12. Campbell RE, et al. Proc. Natl. Acad. Sci. U.S.A 2002;99:7877. [PubMed: 12060735]

13. Merzlyak EM, et al. Nat. Methods 2007;4:555. [PubMed: 17572680]

14. Shaner NC, et al. Nat. Biotechnol 2004;22:1567. [PubMed: 15558047]

15. Bonsma S, Purchase R, Jezowski S, Gallus J, Könz, Völker S. Chem. Phys. Chem 2005;6:838. [PubMed: 15884066]

16. Nifosi R, Luo Y. J. Phys. Chem. B 2007;111:14043. [PubMed: 18027922]

17. Drobizhev M, Makarov NS, Hughes T, Rebane A. J. Phys. Chem. B 2007;111:14051. [PubMed: 18027924]

18. Gross LA, Baird GS, Hoffman RC, Baldridge KK, Tsien RY. Proc. Natl. Acad. Sci. U.S.A 2000;97:11990. [PubMed: 11050230]

19. Shu X, Shaner NC, Yarbrough CA, Tsien RY, Remington SJ. Biochem 2006;45:9639. [PubMed: 16893165]

20. Remington SJ, et al. Biochem 2005;44:202. [PubMed: 15628861]

21. Karotki A, et al. J. Opt. Soc. Am. B 2003;20:321.

22. Kredel S, et al. Chem. Biol 2008;15:224. [PubMed: 18355722]

23. Ward, WW. Green Fluorescent Protein: Properties, Applications and Protocols. Chalfie, M.; Kain, SR., editors. Hoboken, N. J: Wiley; 2005. p. 39-65.

24. Hendrix J, Flors C, Dedecker P, Hofkens J, Engelborghs Y. Biophys. J 2008;94:4103. [PubMed: 18234806]

25. Robinson LC, Marchant JS. Biophys. J 2005;88:1444. [PubMed: 15556986]

26. Shaner NC, et al. Nat. Methods 2008;5:545. [PubMed: 18454154]

27. Bulina ME, et al. Nat. Protocols 2006;1:947.

28. Habuchi S, et al. Proc. Natl. Acad. Sci. U.S.A 2005;102:9511. [PubMed: 15972810]

29. Huang S, Heikal AA, Webb WW. Biophys. J 2002;82:2811. [PubMed: 11964266]

J Phys Chem B. Author manuscript; available in PMC 2010 January 29. 
Transition wavelength, $\mathrm{nm}$
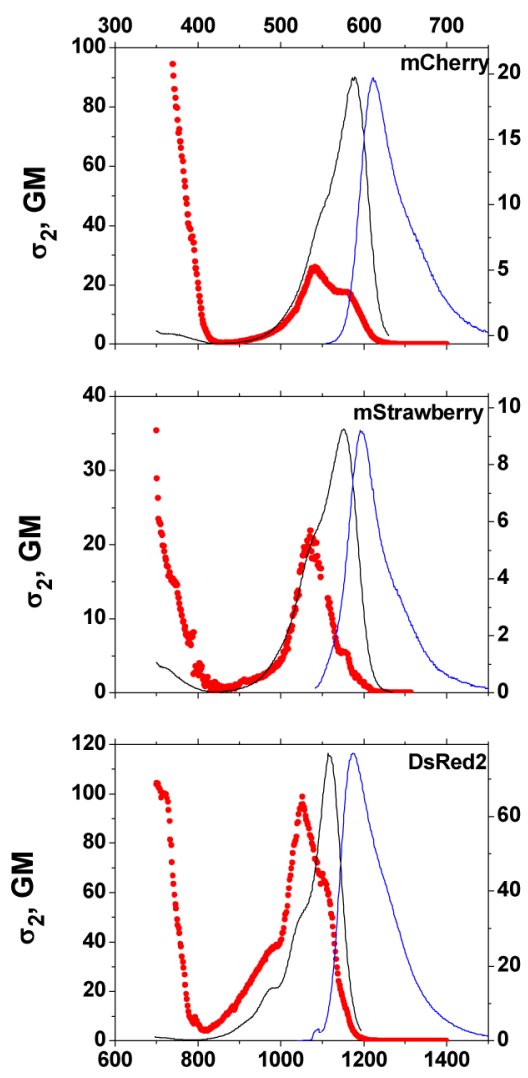

Laser wavelength, $\mathrm{nm}$
Transition wavelength, $\mathrm{nm}$
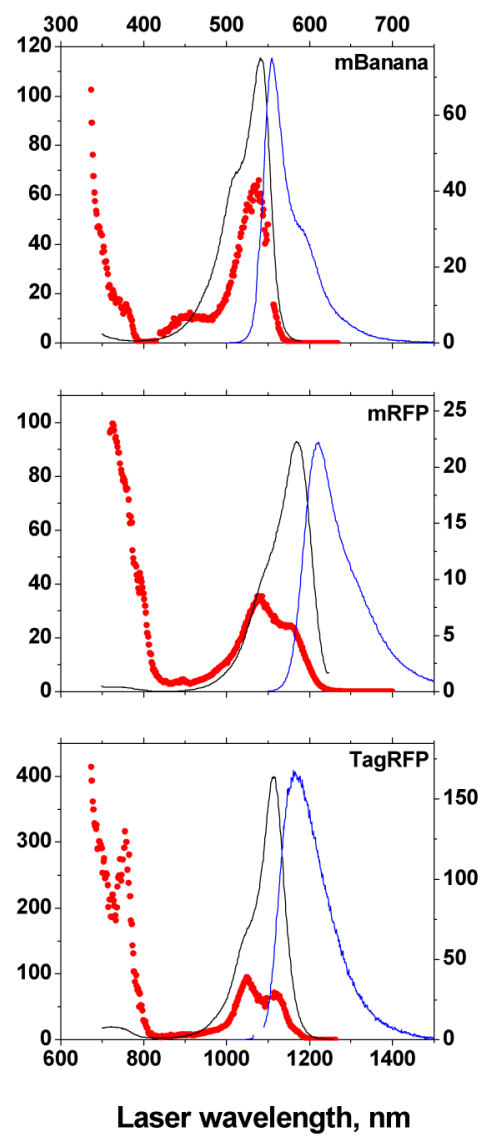

Transition wavelength, $\mathbf{n m}$
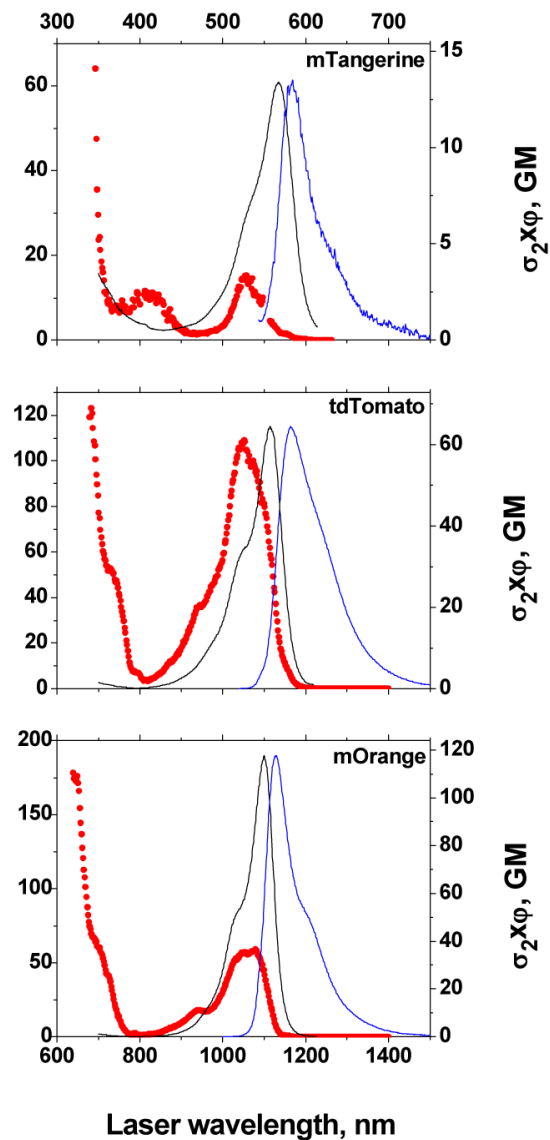

Figure 1.

2PA spectra of orange and red FPs (symbols) shown along with fluorescence emission (blue line) and one-photon fluorescence excitation (black line) spectra. Left vertical scale shows 2PA cross section. Scale on the right represents two-photon brightness. One-photon excitation and emission spectra are shown in arbitrary units. 
mCherry
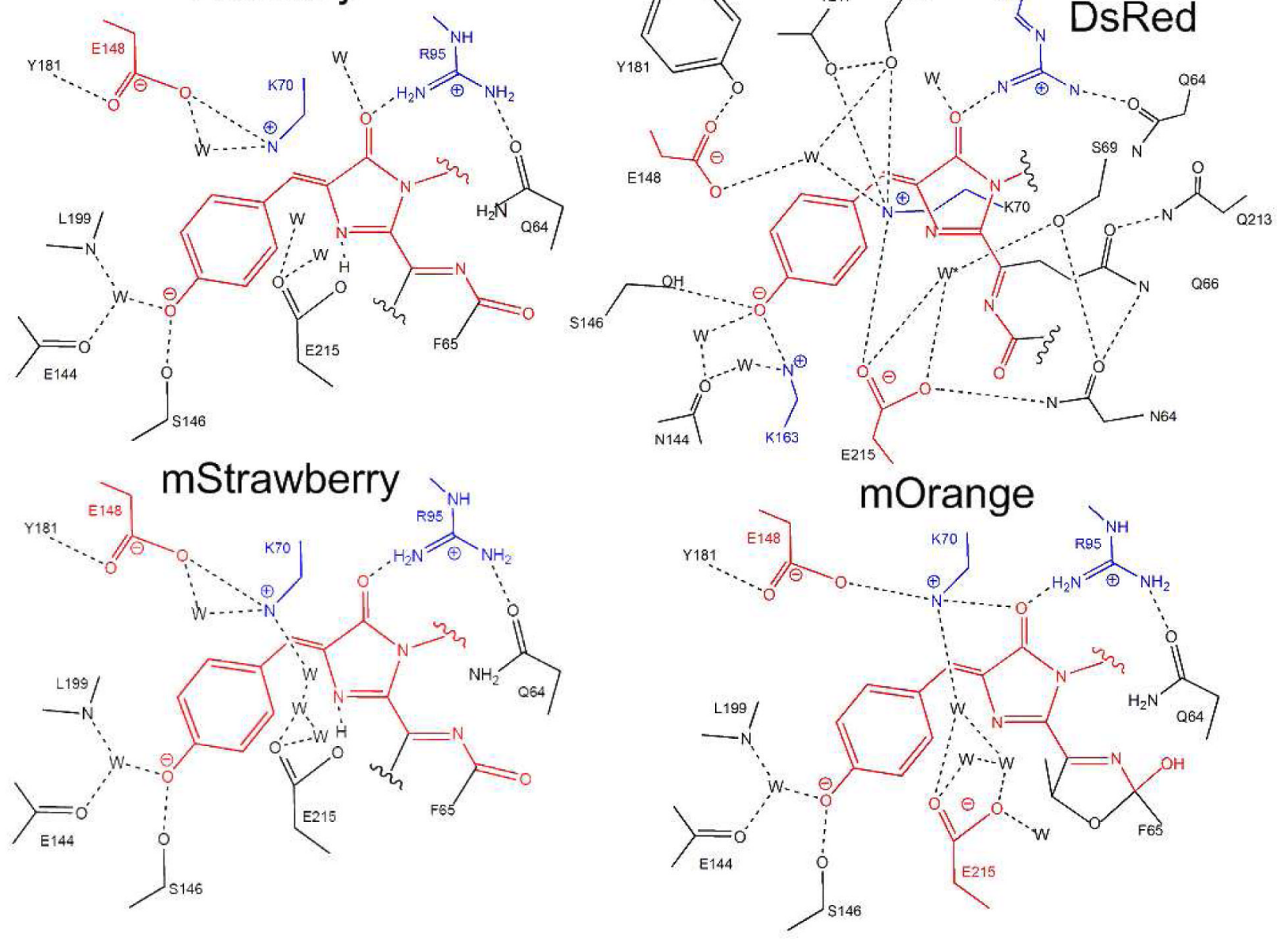

Figure 2.

Schematic diagram of mCherry, mStrawberry, mOrange, and DsRed chromophore environment 19,20 . Hydrogen bonds are shown in dashed lines, charged groups are highlighted with color (blue - for positive, red - for negative), water molecules are designated as W. 


\begin{tabular}{|c|c|c|c|c|c|c|c|c|c|c|}
\hline & 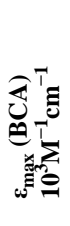 & 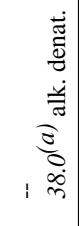 & 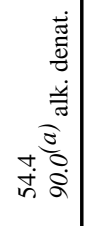 & 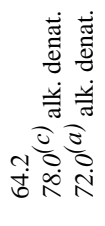 & 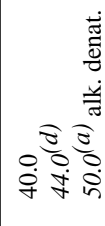 & 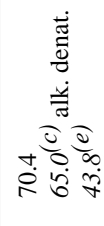 & 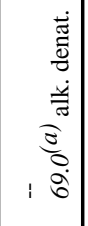 & 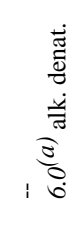 & 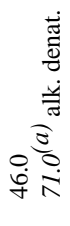 & 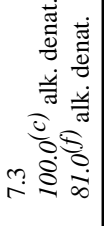 \\
\hline 8 & 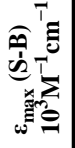 & fे & $\begin{array}{l}\infty \\
i f \\
i f j\end{array}$ & 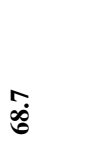 & के & 今. & J્త & $\hat{\partial \theta}$ & & $\begin{array}{l}0.0 \\
\infty\end{array}$ \\
\hline & 衰 & 占 & in & $\stackrel{\infty}{\infty} \stackrel{\infty}{i n}$ & 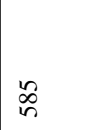 & $\stackrel{\infty}{i n} i^{n}$ & $\stackrel{\infty}{i n n}$ & Ff & in & in \\
\hline & 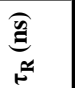 & $\stackrel{n}{=}$ & 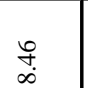 & fo & $\stackrel{\infty}{n} \stackrel{n}{?}$ & तु & ffo & $\underset{\mathfrak{q}}{\mathfrak{g}}$ & : & 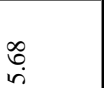 \\
\hline & $\theta$ & శ్ & 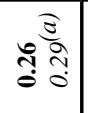 & శ్ర్ల & 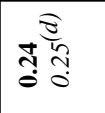 & 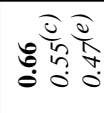 & 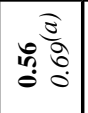 & 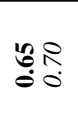 & لَ: & 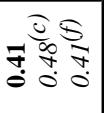 \\
\hline$\frac{1}{\sqrt{2}}$ & 毫 & iु & สิ) & 9 & $\underset{\substack{-\infty \\
-\infty}}{-}$ & $\underset{m}{+}$ & $\stackrel{8}{\circ}$ & तु & त) & 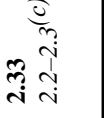 \\
\hline & 产 & 欯 & 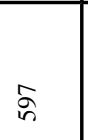 & $\overline{\bar{\sigma}}$ & $\frac{8}{b}$ & 㐫 & 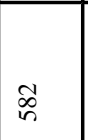 & 苫 & 象 & $\stackrel{\infty}{\infty}$ \\
\hline & 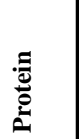 & 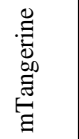 & $\begin{array}{l}\text { E. } \\
\text { D. } \\
\text { 离 } \\
\text { E. }\end{array}$ & 童 & 管 & 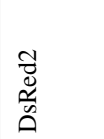 & 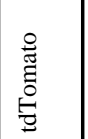 & 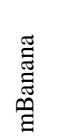 & 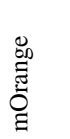 & 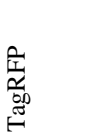 \\
\hline
\end{tabular}

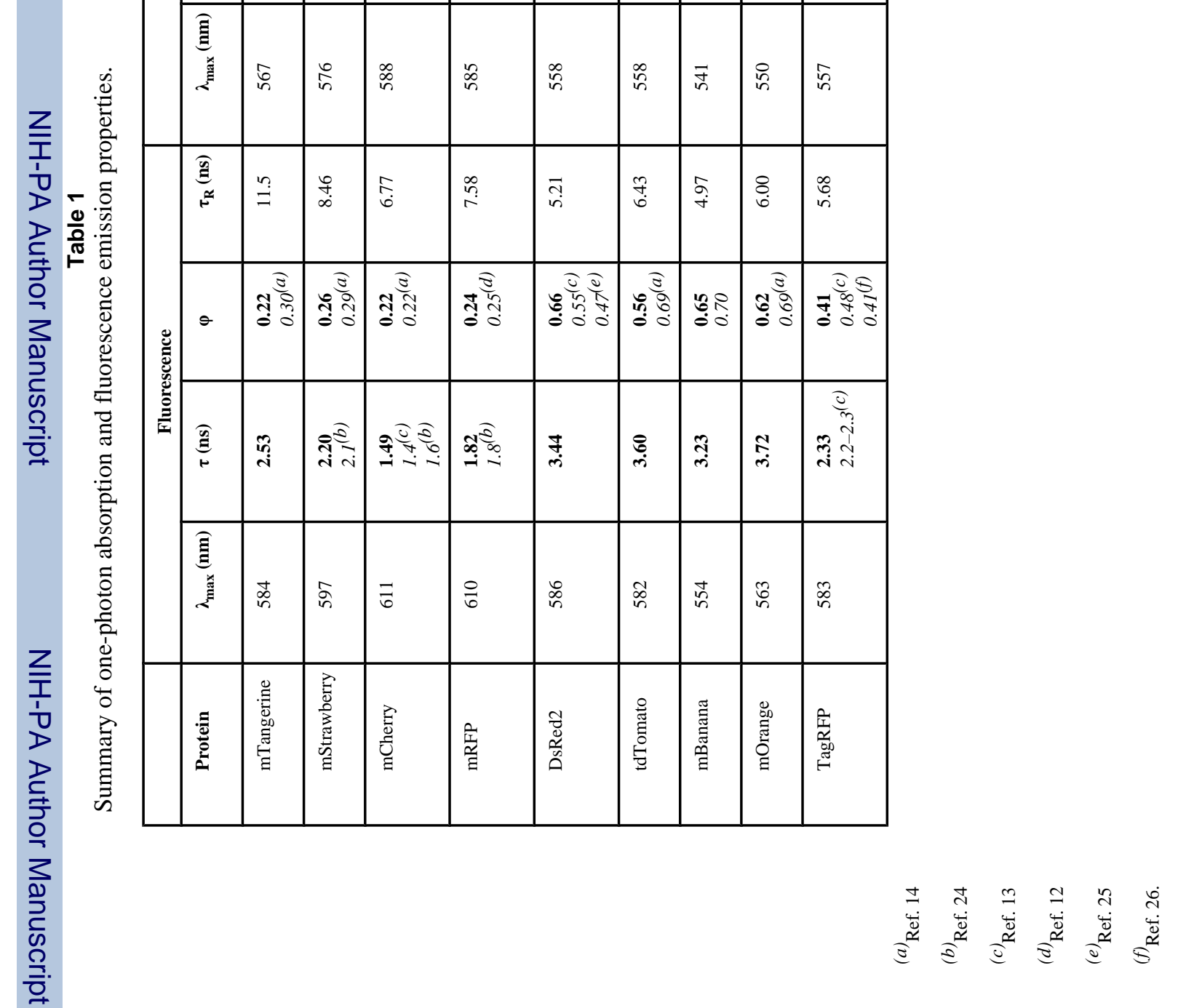




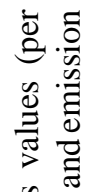

峁势

동

흐를

है

ฮั ঠे

일

苍

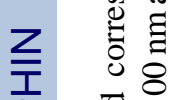

\begin{tabular}{|c|c|c|c|c|c|c|c|c|c|c|}
\hline 遏 & 因 & $\begin{array}{c} \pm \\
⿱ 亠 䒑 \\
n\end{array}$ & 命 & $\bar{\sigma}$ & $\frac{0}{6}$ & $\begin{array}{l}\infty \\
i \\
i n\end{array}$ & $\underset{\infty}{\infty}$ & 点 & 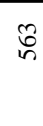 & 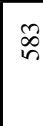 \\
\hline 产 & $\theta$ & \begin{tabular}{l}
$\tilde{y}$ \\
\hdashline
\end{tabular} & 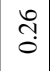 & ป̂. & $\stackrel{\text { J̦ }}{0}$ & $\begin{array}{l}\stackrel{0}{0} \\
0\end{array}$ & 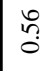 & : & S. & $\bar{\sigma}$ \\
\hline
\end{tabular}

บ ่

$D$
$>$

은 吾

\.

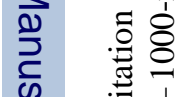

$\frac{0}{60}$

ㅎํㅇ를

产 嘉

表 $\frac{\overline{0}}{0}$

节苛

흥 उ

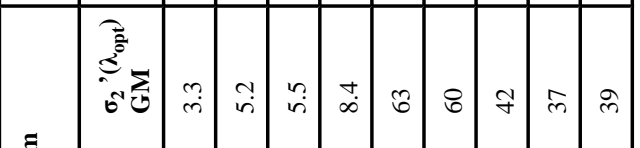

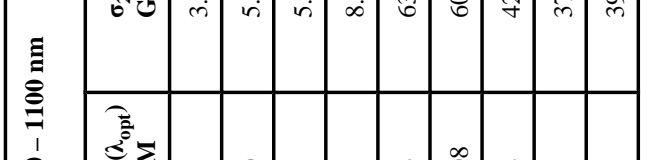

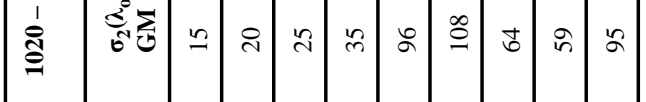

ร)

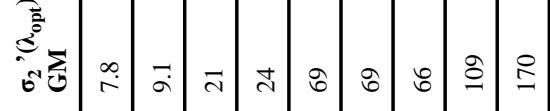

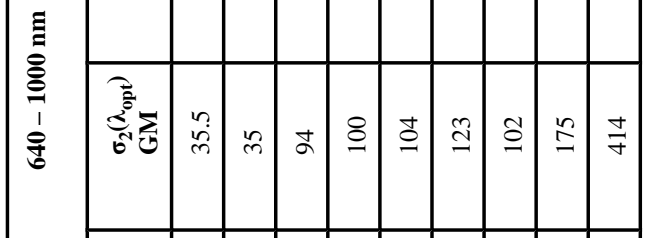

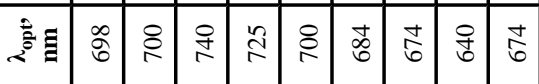

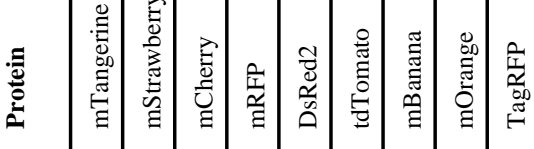

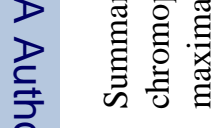

 